\title{
Role of multi-detector CT in analysis of the greater and lesser palatine foramina
}

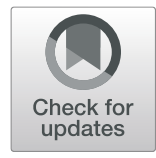

\author{
Ahmad Sayed Awad ${ }^{1 *} \mathbb{D}$, Hadeer Maher Ahmed Tohamy², Hanan Nabieh Gadallah², \\ Mohamed Emad El-Din Ibrahim ${ }^{2}$ and Tarek Ahmed Raafat ${ }^{3}$
}

\begin{abstract}
Background: The objective of this study was to assess variation in number, size, shape, and location of greater and lesser palatine foramina using multiple anatomical landmarks through data obtained from adult head CT scans. CT skulls of 200 adult persons were included in this study. There were 100 males and 100 females, aged from 22 to 65 years old. An e-film DICOM viewer version 2 was applied to estimate morphological parameters and to calculate the linear measurements related to the greater palatine foramen.

Results: On the basis of CT findings, regarding the position of GPF in relation to maxillary molar teeth, the most frequent location was opposite the third maxillary molar (41\%). Regarding the dimensions of the GPF, the mean AP diameter was $3.94 \pm 1.13 \mathrm{~mm}$ on the right side and $4.22 \pm 1.21 \mathrm{~mm}$ on the left. The mean LM diameter was $2.17 \pm$ $0.59 \mathrm{~mm}$ on the right side and $2.28 \pm 0.74 \mathrm{~mm}$ on the left. It was concluded that the GPF was AP elongated in $90.5 \%$ and circular in $9.5 \%$ of the examined CT scans. Linear measurements from the center of GPF to surrounding anatomical landmarks were done and showed no statistically significant difference existed between sides, but a statistically highly significant difference existed between males and females.

Conclusions: Proper localization of GPF is important to facilitate therapeutic, local anesthetic, and surgical manipulation in the maxillofacial region. Based on CT findings, we demonstrated that the GPF is most often located opposite the M3 in the majority of the cases. The maxillary molars are the best landmarks for locating the GPF.
\end{abstract}

Keywords: Greater palatine foramen, Location, CT

\section{Background}

The hard palate presents many important features including the greater and lesser palatine foramina. The lesser palatine foramina (LPF) transmit lesser palatine vessels as well as middle and posterior palatine nerves. The greater palatine foramen (GPF) transmits greater palatine nerve and vessels. Greater palatine nerve is a branch of maxillary division of trigeminal nerve supplying mucosa of hard palate, medial wall of maxillary sinus, and posterior aspect of lateral wall of nose [1]. The greater palatine artery originates from descending palatine branch of maxillary artery in the pterygopalatine

\footnotetext{
* Correspondence: ahmedawad@kasralainy.edu.eg

'Department of Diagnostic and Interventional Radiology, Kasr Al Ainy Faculty of Medicine, Cairo University, Cairo, Egypt

Full list of author information is available at the end of the article
}

fossa, passes through the greater palatine canal, and emerges from GPF in palatal aspect of the third maxillary molar, to reach the hard palate [2]. The palatine crest is a prominent bony ridge extending medially from behind GPF [3].

Locating the greater palatine foramen is of paramount importance for both dentists and oral and maxillofacial surgeons [4]. Furthermore, it is important to determine the location of the GPF for palatal donor tissue and greater palatine nerve block anesthesia. Knowing the exact location of the GPF is essential also for mobilization of the greater palatine artery in closure of oroantral fistula using mucoperiosteal pedicled palatal flaps [5]. It is also reported that stimulation of pterygopalatine ganglion through this foramen is used for diminishing the effects of paralysis in paralytic patients

\section{Springer Open}

(อ) The Author(s). 2020 Open Access This article is licensed under a Creative Commons Attribution 4.0 International License, which permits use, sharing, adaptation, distribution and reproduction in any medium or format, as long as you give appropriate credit to the original author(s) and the source, provide a link to the Creative Commons licence, and indicate if changes were made. The images or other third party material in this article are included in the article's Creative Commons licence, unless indicated otherwise in a credit line to the material. If material is not included in the article's Creative Commons licence and your intended use is not permitted by statutory regulation or exceeds the permitted use, you will need to obtain permission directly from the copyright holder. To view a copy of this licence, visit http://creativecommons.org/licenses/by/4.0/. 
and also in cases of cerebral vasospasmor cluster and migraine headache [6].

The objective of this study was to assess variation in number, size, shape, and location of greater and lesser palatine foramina using multiple anatomical landmarks through data obtained from adult head CT scans.

\section{Methods}

CT skulls for examination of the brain or paranasal sinuses of 200 adult persons were included in this study. There were 100 males and 100 females, aged from 22 to 65 years old.

- Inclusion criteria: CT skulls for examination of brain or paranasal sinuses of adult persons of both sexes.

- Exclusion criteria: radiographs showing pathological changes in the region of maxilla (including developmental and traumatic changes).

This study was approved by the Research Ethics Committee. Written informed consent was obtained from all the study patients before any data or scans were gathered or performed.

A high-speed GE FX CT scanner (GE Healthcare) acquired CT images at exposure $120 \mathrm{kV}, 74 \mathrm{~mA}, 60 \mathrm{mAs}$; rotation time 0.5; and slice thickness $0 . \mathrm{mm}$.

Patient's sex and age data were acquired from patient files.

An e-film DICOM viewer version 2, a program for radiograph analysis and measurement, was applied to estimate morphological parameters and to calculate the linear measurements. Images were evaluated in axial, coronal, and sagittal planes.

\section{Morphological parameters}

1. Number of lesser palatine foramina on both sides.

2. Presence of palatine crest on both sides.

3. Location of the GPF in relation to maxillary molar teeth. The location of GPF was described as either opposite the second maxillary molar (M2), between M2 and M3, opposite M3, or behind M3.

The location of the GPF were determined by the following steps:

a. The screen was divided on the e-film viewer into two parts (A and B).

b. The same axial cuts were retrieved in both parts.

c. A transverse line passing through the center of GPF in image B was drawn.

d. Another line parallel to the first one was drawn in image A.

e. A new depth of axial reconstruction demonstrated an overlap between the previous two lines, thus locating the GPF in relation to maxillary molar teeth.

\section{Morphometric parameters}

The dimensions of the GPF were estimated as follows:

a. The longest anteroposterior (AP) and lateral-medial (LM) dimensions were measured.

b. The center of GPF was set at the point of intersection of the longest AP and LM dimensions.

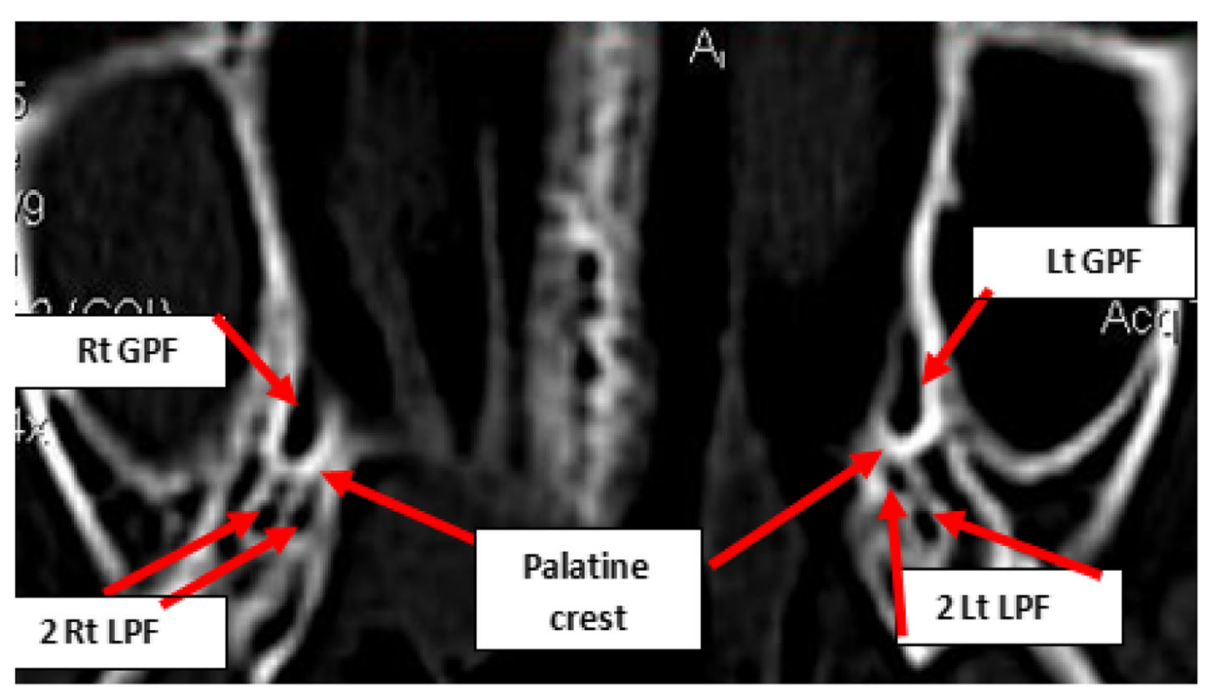

Fig. $1 \mathrm{~A} C T$ scan at the region of hard palate illustrating the greater and lesser palatine foramina as well as the presence of palatine crest on both sides 


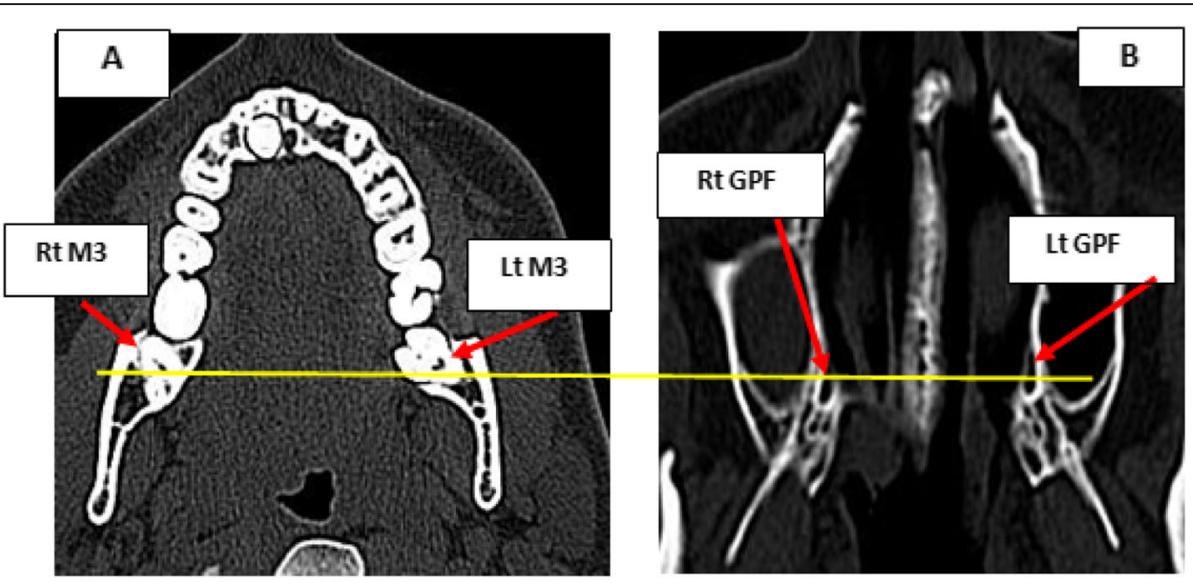

Fig. 2 A CT scan at the region of hard palate illustrating the right and left greater palatine foramina (b) located opposite the right and left third maxillary molars (M3) (a)

c. The shape (or form) of GPF was determined by dividing AP by LM dimensions:

- Values equal to one indicate a circular foramen

- Values greater than one indicate an AP elongated foramen

- Values less than one indicate a LM elongated foramen

Measurements on CT scans were obtained from the center of GPF to:

1. Posterior border of hard palate (PBHP) (shortest distance).

2. Midline maxillary suture (MMS) (shortest perpendicular distance).

3. Posterior nasal spine (PNS).

4. Center of incisive fossa (IF).

\section{Center of opposite GPF.}

\section{Statistical study}

Statistical analysis was performed using statistical package for social sciences (SPSS) version 21.0 (IBM corporation, Somers, NY, USA) statistical software. The frequency of nominal data was done. The association among the different nominal variables regarding side and gender was explored using Chi square $\left(X^{2}\right)$ tests.

The quantitative data were expressed as means \pm standard deviation (SD). The data were examined by Kolmogorov Smirnov test for normality. Independent $t$ test was performed to compare between the different variables regarding side and gender.

The results were considered significant at $p$ value $\leq$ 0.05 and highly significant at $p$ value $\leq 0.01$.
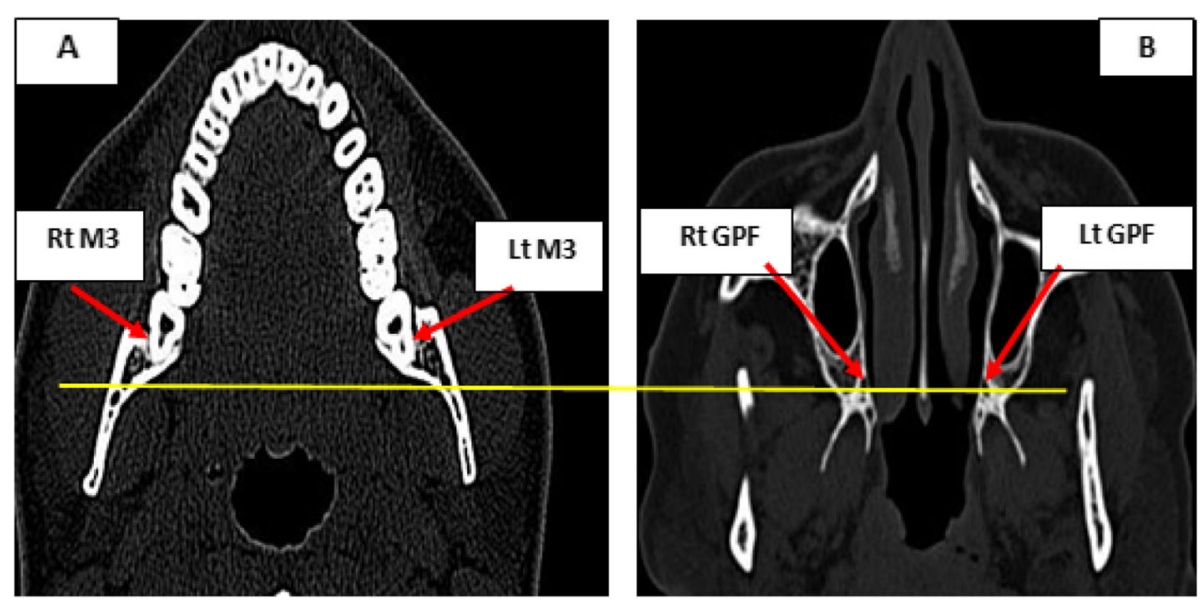

Fig. $3 \mathrm{~A} \subset T$ scan at the region of hard palate illustrating the right and left greater palatine foramina (b) located behind the right and left third maxillary molars (M3) (a) 


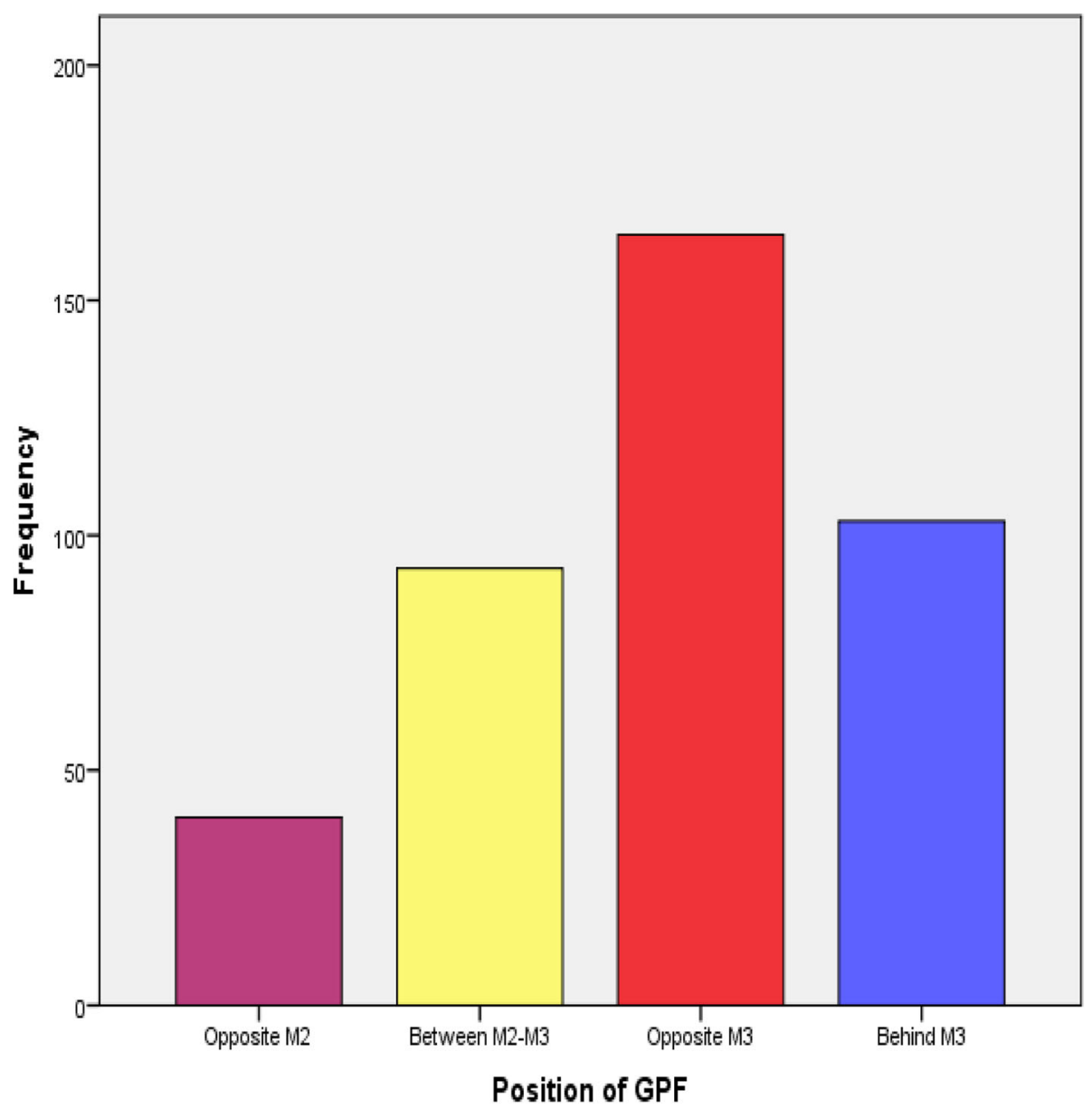

Fig. 4 Bar chart of the frequency of position of the greater palatine (GPF) in CT scans

\section{Results}

Morphological parameters

Location of GPF in relation to maxillary molar teeth

The presence of one GPF on both sides was a constant finding (Fig. 1). The GPF was most frequently located opposite M3 (41\%) (Fig. 2). It was found behind M3 in

Table 1 Frequency and percent of position of the GPF based

\begin{tabular}{|c|c|c|c|c|}
\hline \multirow[t]{2}{*}{ Position of GPF } & \multicolumn{2}{|l|}{ Side } & \multirow[t]{2}{*}{ Total } & \multirow{2}{*}{$\begin{array}{l}p \\
\text { value }\end{array}$} \\
\hline & Right & Left & & \\
\hline \multirow[t]{2}{*}{ Opposite M3 } & 80 & 84 & 164 & \multirow[t]{10}{*}{0.2 (NS) } \\
\hline & $40.0 \%$ & $42.0 \%$ & $41.0 \%$ & \\
\hline \multirow[t]{2}{*}{ Opposite M2 } & 20 & 20 & 40 & \\
\hline & $10.0 \%$ & $10.0 \%$ & $10.0 \%$ & \\
\hline \multirow[t]{2}{*}{ Between $\mathrm{M} 2$ and $\mathrm{M} 3$} & 48 & 45 & 93 & \\
\hline & $24.0 \%$ & $22.5 \%$ & $23.2 \%$ & \\
\hline \multirow[t]{2}{*}{ Behind M3 } & 52 & 51 & 103 & \\
\hline & $26.0 \%$ & $25.5 \%$ & $25.8 \%$ & \\
\hline \multirow[t]{2}{*}{ Total } & 200 & 200 & 400 & \\
\hline & $100.0 \%$ & $100.0 \%$ & $100.0 \%$ & \\
\hline
\end{tabular}
25.8\% (Fig. 3), between M2 and M3 in 23.3\%, and opposite M2 in 10\% (Fig. 4). Regarding the side, on the right side, the GPF was located opposite M3 in 40\%, behind

Table 2 Frequency and percent of position of the GPF based on gender

\begin{tabular}{|c|c|c|c|c|c|c|}
\hline \multirow[t]{2}{*}{ Gender } & \multicolumn{4}{|c|}{ Position of GPF } & \multirow[t]{2}{*}{ Total } & \multirow{2}{*}{$\begin{array}{l}p \\
\text { value }\end{array}$} \\
\hline & $\begin{array}{l}\text { Opposite } \\
\text { M2 }\end{array}$ & $\begin{array}{l}\text { Between M2 } \\
\text { and M3 }\end{array}$ & $\begin{array}{l}\text { Opposite } \\
\text { M3 }\end{array}$ & $\begin{array}{l}\text { Behind } \\
\text { M3 }\end{array}$ & & \\
\hline \multirow[t]{2}{*}{ Male } & 8 & 54 & 95 & 43 & 200 & \multirow{2}{*}{$\begin{array}{l}0.3 \\
\text { (NS) }\end{array}$} \\
\hline & $4.0 \%$ & $27.0 \%$ & $47.5 \%$ & $21.5 \%$ & $100.0 \%$ & \\
\hline \multirow[t]{2}{*}{ Female } & 32 & 39 & 69 & 60 & 200 & \\
\hline & $16.0 \%$ & $19.5 \%$ & $34.5 \%$ & $30.0 \%$ & $100.0 \%$ & \\
\hline \multirow[t]{2}{*}{ Total } & 40 & 93 & 164 & 103 & 400 & \\
\hline & $10.0 \%$ & $23.2 \%$ & $41.0 \%$ & $25.8 \%$ & $100.0 \%$ & \\
\hline
\end{tabular}



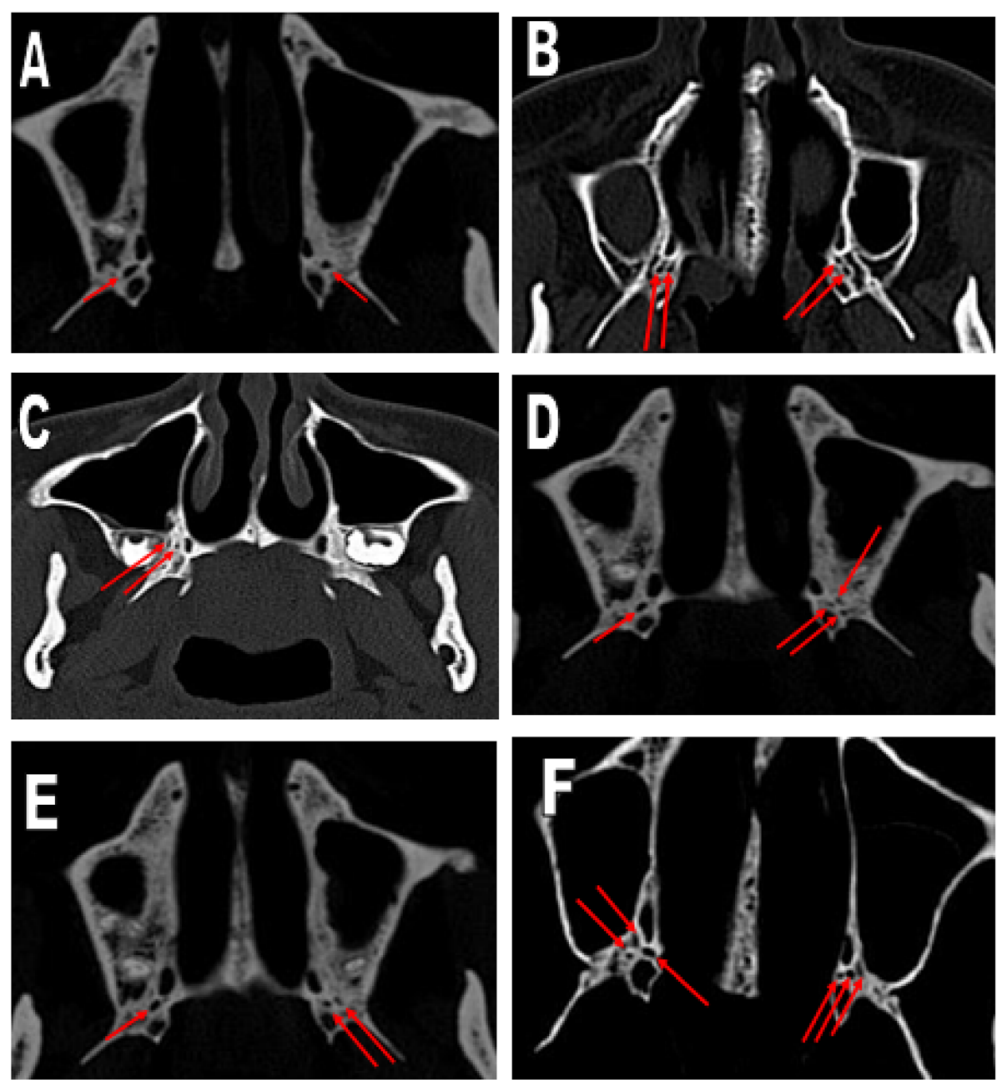

Fig. 5 A CT scan at the region of the hard palate in different patients. a Single LPF on both sides. b Two LPF on both sides. c Two right LPF and absent left. $\mathbf{d}$ Single LPF on the right side and 3 LPF on left side. e Single LPF on the right and two LPF on left side. $\mathbf{f}$ Three LPF on both sides

M3 in 26\%, between M2 and M3 in 24\%, and opposite M2 in $10 \%$. On the left side, it was located opposite M3 in $42 \%$, behind $\mathrm{M} 3$ in $25.5 \%$, between M2 and M3 in $22.5 \%$, and opposite $\mathrm{M} 2$ in $16 \%$. $p$ value $=0.2$ is statistically non-significant using Chi square tests (Table 1).

Table 3 Number, frequency, and percent of lesser palatine foramina

\begin{tabular}{lllll}
\hline $\begin{array}{l}\text { Frequency of } \\
\text { lesser palatine } \\
\text { foramina }\end{array}$ & Side & & Total & $p$ value \\
\cline { 2 - 3 } No foramina & 0 & Left & & \\
\hline \multirow{2}{*}{ One foramen } & 152 & 2 & 2 & 0.5 (NS) \\
& $76.0 \%$ & $1.0 \%$ & $0.5 \%$ & \\
Two foramina & 46 & $75.0 \%$ & $75.5 \%$ & \\
& $23.0 \%$ & $21.0 \%$ & $22.0 \%$ & \\
Three foramina & 2 & 6 & 8 & \\
& $1.0 \%$ & $3.0 \%$ & $2.0 \%$ & \\
Total & 200 & 200 & 400 & \\
& $100.0 \%$ & $100.0 \%$ & $100.0 \%$ & \\
\hline
\end{tabular}

Regarding the location of GPF in relation to maxillary molars in both males and females, several locations were encountered, opposite M3 in $47.5 \%$ of males and $34.5 \%$ of females, between M2 and M3 in 27\% of males and $19.5 \%$ of females, behind M3 in $21.5 \%$ of males and $30 \%$ of females, and opposite M2 in $4 \%$ of males and 16\% of females. $p$ value $=0.3$ is statistically non-significant using Chi square tests (Table 2).

Table 4 Number, frequency, and percent of lesser palatine foramina based on gender

\begin{tabular}{llllll}
\hline Gender & \multicolumn{4}{l}{ Number of lesser palatine foramina } & Total \\
\cline { 2 - 5 } & No & One & Two & Three & \\
\hline Male & 2 & 152 & 46 & 0 & 200 \\
& $1.0 \%$ & $76.0 \%$ & $23.0 \%$ & $0.0 \%$ & $100.0 \%$ \\
Female & 0 & 150 & 42 & 8 & 200 \\
& $0.0 \%$ & $75.0 \%$ & $21.0 \%$ & $4.0 \%$ & $100.0 \%$ \\
Total & 2 & 302 & 88 & 8 & 400 \\
& $0.5 \%$ & $75.5 \%$ & $22.0 \%$ & $2.0 \%$ & $100.0 \%$ \\
\hline
\end{tabular}




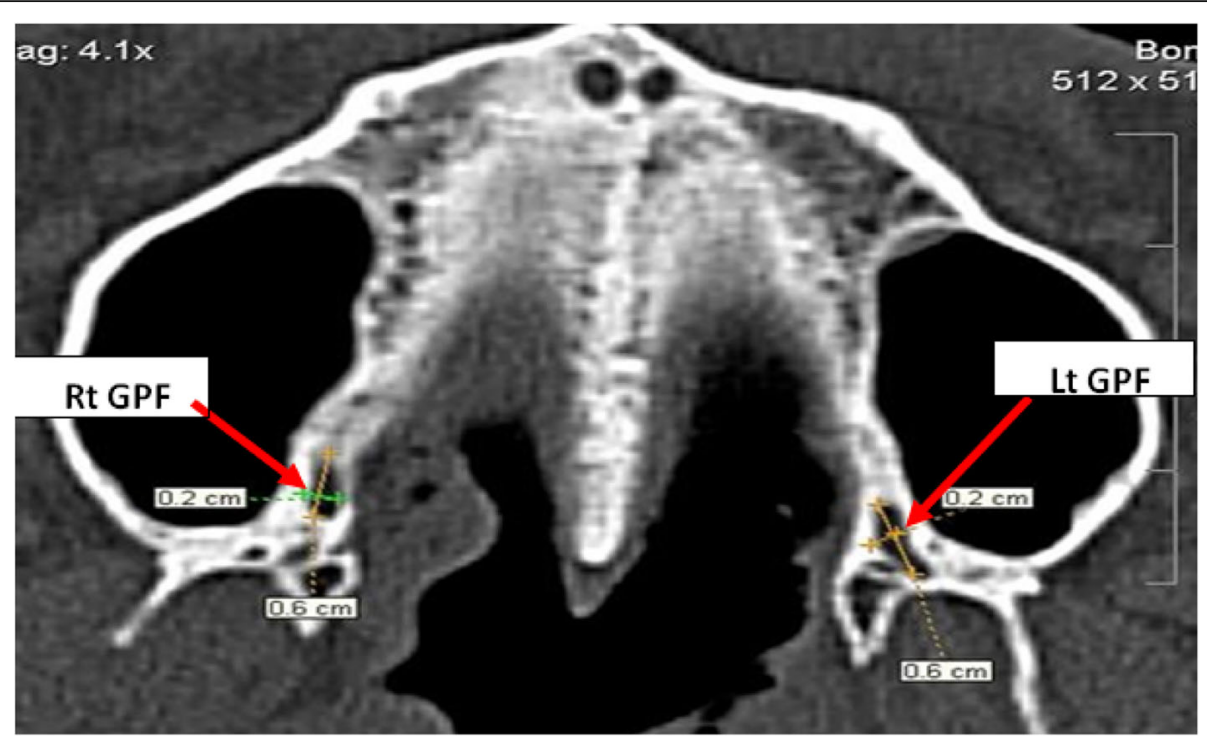

Fig. 6 A CT scan at the region of hard palate illustrating the dimensions of the greater palatine foramina (GPF)

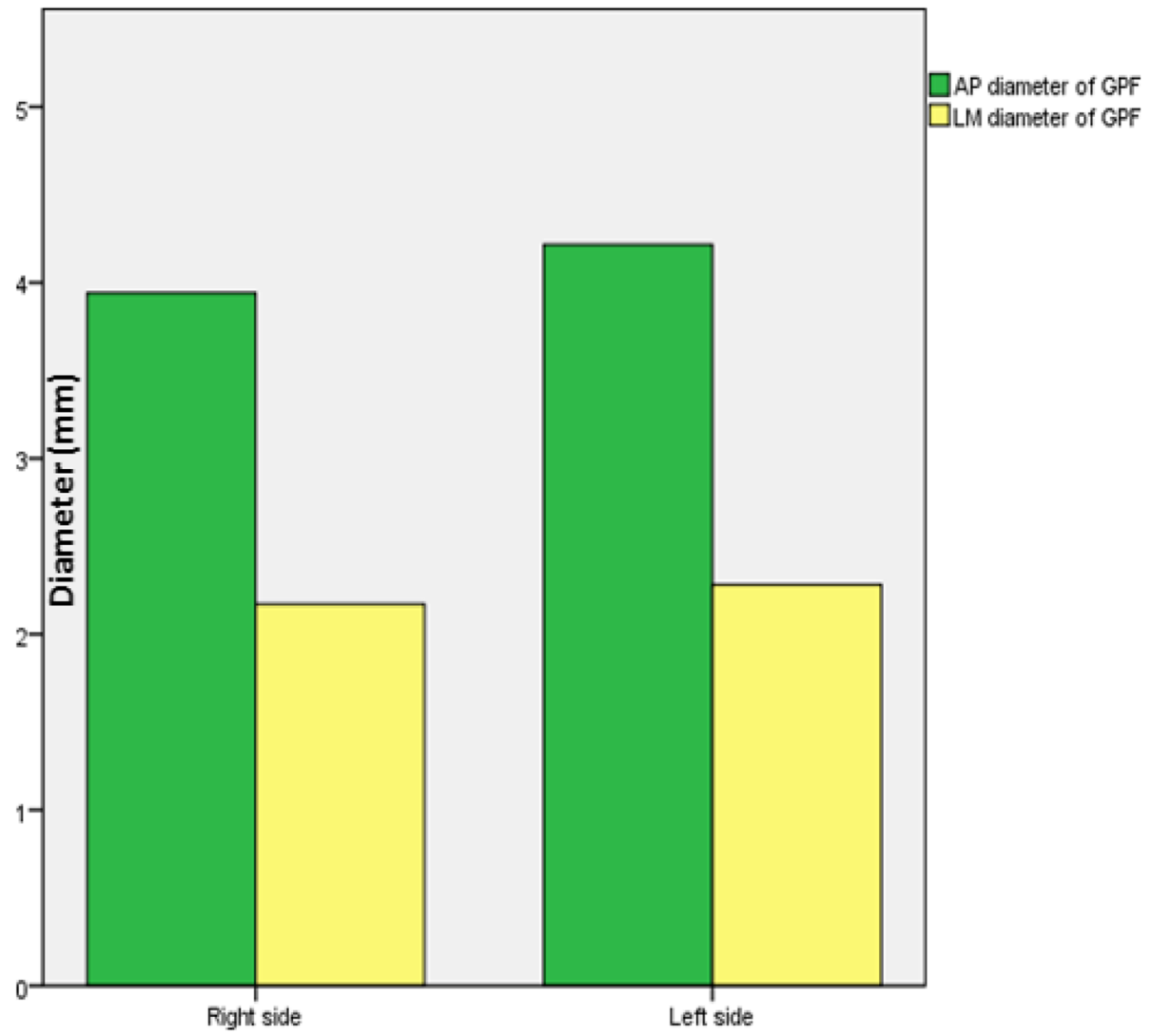

Fig. 7 Bar chart of the dimensions of the greater palatine foramen (GPF) in CT scans based on side 
Table 5 The dimensions of the GPF based on side

\begin{tabular}{lllll}
\hline Dimensions of GPF & Side & $N$ & Mean \pm SD & $p$ value \\
\hline AP dimension-GPF $(\mathrm{mm})$ & Right & 200 & $3.94 \pm 1.13$ & 0.02 \\
& Left & 200 & $4.22 \pm 1.21$ & \\
LM dimension-GPF $(\mathrm{mm})$ & Right & 200 & $2.17 \pm 0.59$ & 0.09 \\
& Left & 200 & $2.28 \pm 0.74$ & \\
\hline
\end{tabular}

\section{Number of lesser palatine foramina (LPF) (Fig. 5)}

The presence of one lesser palatine foramen (LPF) was most frequent $(75.5 \%)$. Two LPF were observed in $22 \%$ and three foramina in $22 \%$. Absent foramina were encountered in $0.5 \%$. Regarding the side, on the right side, one foramen existed in $76 \%$, two foramina in $23 \%$, and three in $1 \%$. On the left side, one foramen existed in $75 \%$, two foramina in $21 \%$, and three in $3 \%$, and absent foramina were encountered in $1 \% . p$ value $=0.5$ is statistically non-significant using Chi square tests (Table 3 ).

Regarding the gender, males showed absent LPF in $1 \%$, one foramen in $76 \%$, and two foramina in $23 \%$. Females showed one LPF in $75 \%$, two foramina in $21 \%$, and three foramina in $4 \%$ (Table 4 ).

\section{Presence of palatine crest}

The presence of palatine crest has been a constant finding in all examined CT scans (Fig. 1).

\section{Morphometric parameters}

\section{The dimensions of the greater palatine foramen (GPF)}

On the right side, the mean AP diameter of GPF was $3.94 \pm 1.13 \mathrm{~mm}$, and LM diameter was $2.17 \pm 0.59 \mathrm{~mm}$. On the left side, mean AP diameter was $4.22 \pm 1.21 \mathrm{~mm}$, and LM diameter was $2.28 \pm 0.74 \mathrm{~mm}$ (Figs. 6 and 7). $p$ value $=0.02$ is statistically significant using independent $t$ test (Table 5).

In males, the mean AP diameter of the GPF was 4.39 $\pm 1.2 \mathrm{~mm}$, and the mean LM diameter was $2.47 \pm 0.70$ $\mathrm{mm}$. In females, the mean AP diameter was $3.77 \pm 1.07$ $\mathrm{mm}$, and the mean LM diameter was $1.98 \pm 0.53 \mathrm{~mm} . P$ value less than 0.01 is statistically highly significant using independent $t$ test (Table 6).

The GPF was AP elongated in $90.5 \%$ and circular in 9.5\%. Regarding the side, on the right side, the GPF was AP elongated in $90 \%$ and circular in $10 \%$. On the left

Table 6 The dimensions of the GPF based on gender

\begin{tabular}{lllll}
\hline Dimensions of GPF & Gender & $N$ & Mean \pm SD & $p$ value \\
\hline AP dimension-GPF $(\mathrm{mm})$ & Male & 200 & $4.39 \pm 1.20$ & 0.000 \\
& Female & 200 & $3.77 \pm 1.07$ & \\
LM dimension-GPF $(\mathrm{mm})$ & Male & 200 & $2.47 \pm 0.70$ & 0.000 \\
& Female & 200 & $1.98 \pm 0.53$ & \\
\hline
\end{tabular}

side, it was AP elongated in $91 \%$ and circular in $9 \%$. $p$ value $=0.1$ is statistically non-significant using Chi square tests (Table 7 and Fig. 8).

In males, GPF was AP elongated in $94 \%$ and circular in $6 \%$. In females, it was AP elongated in $87 \%$ and circular in $13 \%$. $p$ value $=0.02$ is statistically significant using Chi square tests (Table 8 ).

\section{Measurements from the center of GPF to surrounding anatomical landmarks}

On the right side, the GPF was positioned $3.9 \pm 1.21$ $\mathrm{mm}$ from PBHP (Fig. 9), $14.95 \pm 1.3 \mathrm{~mm}$ from MMS (Fig. 10), $16.55 \pm 1.61 \mathrm{~mm}$ from PNS (Fig. 11), and 38.06 $\pm 3.10 \mathrm{~mm}$ from IF (Fig. 12). On the left side, the GPF was positioned $3.93 \pm 1.13 \mathrm{~mm}$ from PBHP, $14.99 \pm$ $1.24 \mathrm{~mm}$ from MMS, $16.48 \pm 1.6 \mathrm{~mm}$ from PNS, and $37.96 \pm 3.17 \mathrm{~mm}$ from IF. $P$ value ranges from 0.66 to 0.8 which is statistically non-significant using independent $t$ test (Table 9 and Fig. 13).

The mean distance from the center of GPF to the center of opposite GPF was $30.38 \pm 2.36 \mathrm{~mm}$ (Fig. 14).

In males, the GPF was positioned $4.22 \pm 1.21 \mathrm{~mm}$ from PBHP, $15.37 \pm 1.21 \mathrm{~mm}$ from MMS, $17.13 \pm 1.54 \mathrm{~mm}$ from PNS, and $38.89 \pm 3.28 \mathrm{~mm}$ from IF. In females, the GPF was positioned $3.61 \pm 1.04 \mathrm{~mm}$ from PBHP, $14.57 \pm$ $1.21 \mathrm{~mm}$ from MMS, $\pm 1.42 \mathrm{~mm}$ from PNS, and $37.13 \pm$ $2.70 \mathrm{~mm}$ from IF. $P$ value less than 0.01 indicates statistically highly significant using independent $t$ test (Table 10).

The mean distance from the center of GPF to the center of opposite GPF was $31.22 \pm 2.30 \mathrm{~mm}$ in males (Fig. 14) and $29.54 \pm 2.12 \mathrm{~mm}$ in females. $P$ value less than 0.01 indicates statistically highly significant using independent $t$ test (Table 11).

\section{Discussion}

The hard palate is an essential region of the skull; its gross anatomy and morphological variation have been of interest in several studies. Different clinical problems may require surgical approach to the bony palate such as dentofacial orthopedics, implant-assisted dental

Table 7 Frequency and percent of the shape of the GPF based on side

\begin{tabular}{|c|c|c|c|c|}
\hline \multirow[t]{2}{*}{ Shape of GPF } & \multicolumn{2}{|l|}{ Side } & \multirow[t]{2}{*}{ Total } & \multirow[t]{2}{*}{$p$ value } \\
\hline & $\overline{\text { Right }}$ & Left & & \\
\hline \multirow[t]{2}{*}{ AP elongated } & 180 & 182 & 362 & 0.1 (NS) \\
\hline & $90.0 \%$ & $91.0 \%$ & $90.5 \%$ & \\
\hline \multirow[t]{2}{*}{ Circular } & 20 & 18 & 38 & \\
\hline & $10.0 \%$ & $9.0 \%$ & $9.5 \%$ & \\
\hline \multirow[t]{2}{*}{ Total } & 200 & 200 & 400 & \\
\hline & $100.0 \%$ & $100.0 \%$ & $100.0 \%$ & \\
\hline
\end{tabular}




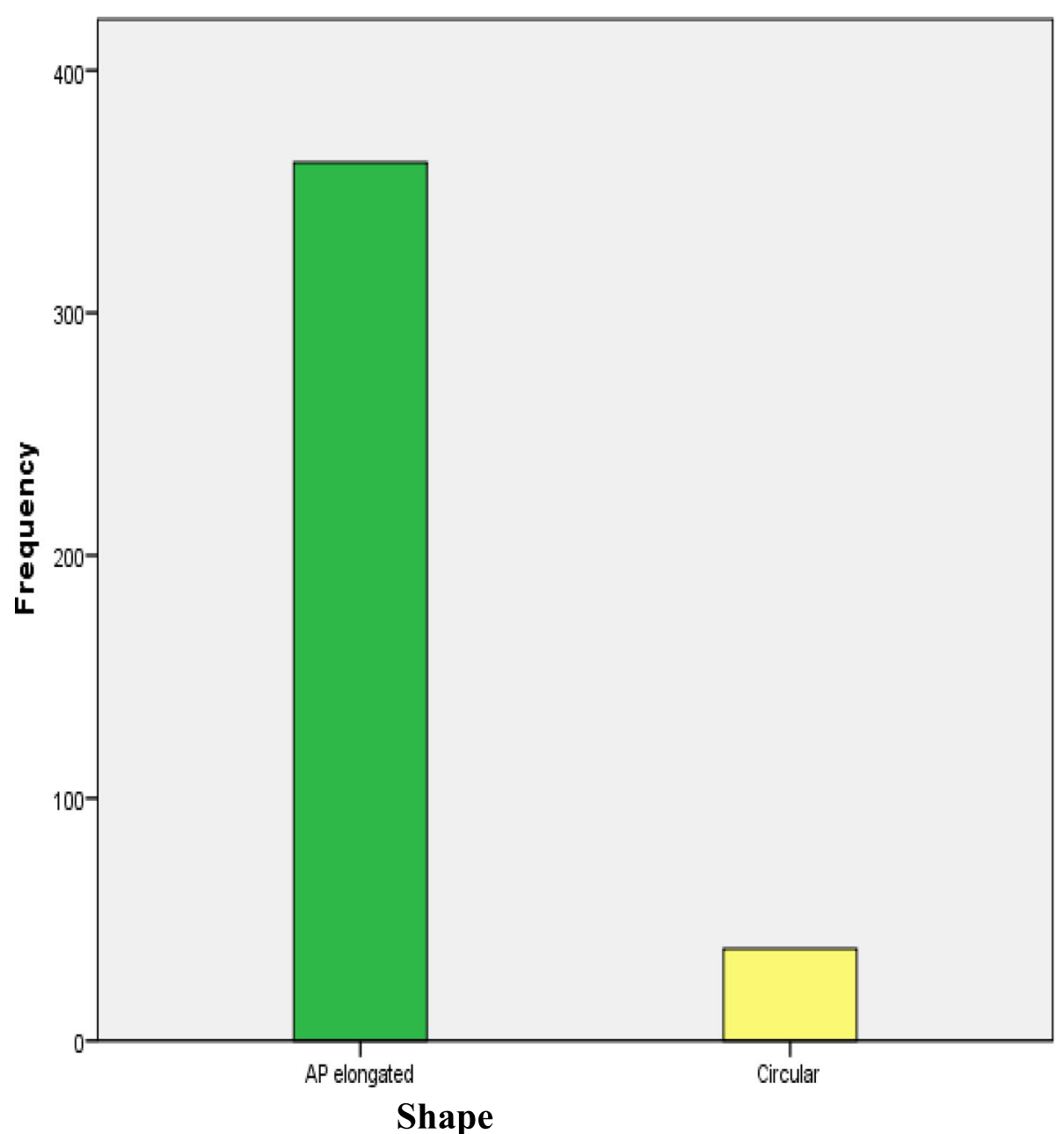

Fig. 8 Bar chart of the frequency of the shape of the greater palatine foramen (GPF) in CT scans

reconstruction of oncology patients, maxillary orthodontic protraction, and obvious oral pathology [1].

Greater palatine canal approach to maxillary nerve block demands a perfect three-dimensional orientation of position, direction, and extent of the canal. The

Table 8 Frequency and percent of the shape of the GPF based on gender

\begin{tabular}{|c|c|c|c|c|}
\hline \multirow[t]{2}{*}{ Gender } & \multicolumn{2}{|l|}{ Shape of GPF } & \multirow[t]{2}{*}{ Total } & \multirow{2}{*}{$\begin{array}{l}p \\
\text { value }\end{array}$} \\
\hline & AP elongated & Circular & & \\
\hline \multirow[t]{2}{*}{ Male } & 188 & 12 & 200 & 0.02 \\
\hline & $94.0 \%$ & $6.0 \%$ & $100.0 \%$ & \\
\hline \multirow[t]{3}{*}{ Female } & 174 & 26 & 200 & \\
\hline & $87.0 \%$ & $13.0 \%$ & $100.0 \%$ & \\
\hline & & & 5 & \\
\hline \multirow[t]{2}{*}{ Total } & 362 & 38 & 400 & \\
\hline & $90.5 \%$ & $9.5 \%$ & $100.0 \%$ & \\
\hline
\end{tabular}

preliminary step is identification of GPF. Utilizing multiple anatomical landmarks to identify the GPF increases the accuracy and minimizes the complications of injecting anesthetic drug [7]. In numerous previous studies using dry adult skulls, there is more emphasis on all the measurements of present study. However, our study, being radiological evaluation, the location of GPF is more accurate than the dry bone studies.

In all examined CT scans, the presence of GPF on both sides was a constant finding. This is consistent with the majority of the surveyed studies $[4,8,9]$. However, discrepancy in the number of GPF has previously been reported by Cagimni et al. [5]. They reported a single GPF in $81 \%$, double GPF in $16 \%$, and triple GPF in $2 \%$ of the examined skulls. Multiple GPF transmit greater palatine neurovascular bundle, similar to the single GPF. The presence of multiple GPF is anticipated when the pain is not effectively blocked during anesthesia [5].

In the present study, the GPF was most frequently located opposite M3 (41\%). Other less frequent locations 


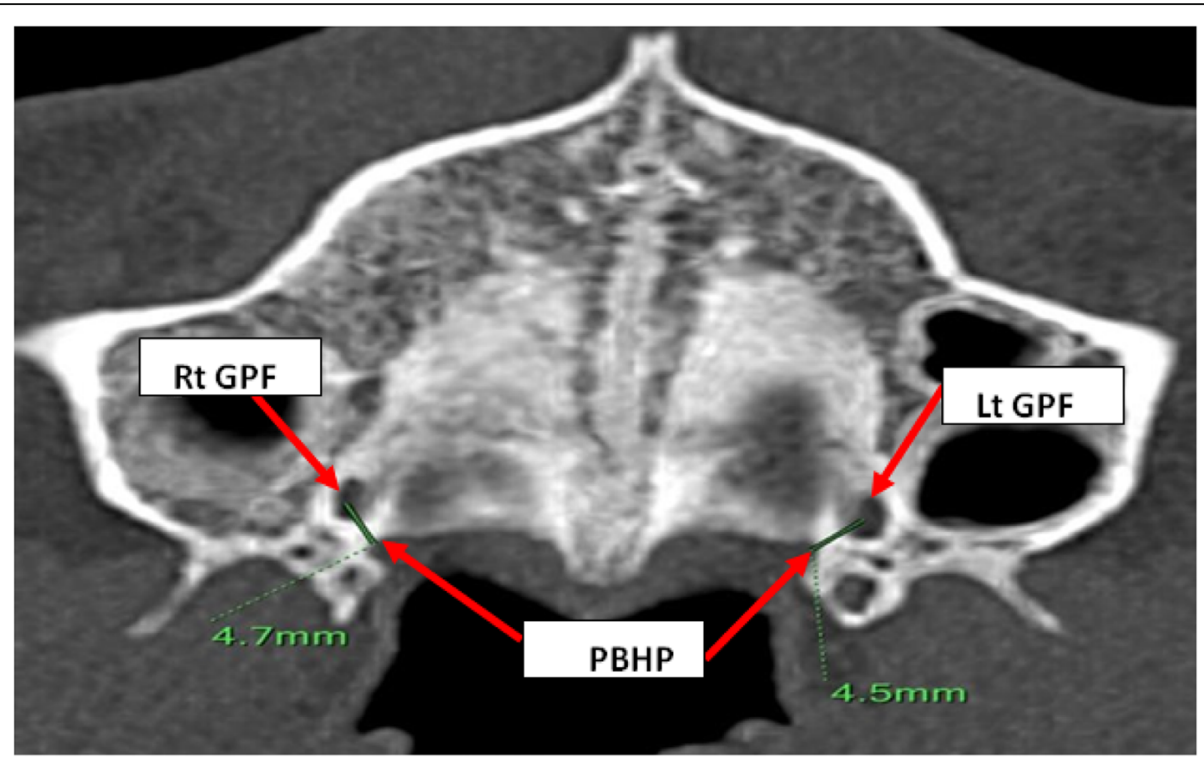

Fig. 9 A CT scan at the region of hard palate illustrating the shortest distance from the center of GPF to posterior border of hard palate (PBHP)

were behind M3 (25.8\%), between M2 and M3 (23.2\%), and opposite M2 (10\%). The same most frequent location (opposite M3) was reported by Shalaby et al. [9] in their study on Egyptian skulls (84\%). Our results also match with Varalakshmi et al. [6] and Beetge et al. [10] who stated that GPFs were close to the third maxillary molar in $69.8 \%$ and $66.65 \%$ of their cases, respectively.
Also, this stands in agreement with Tomaszewska et al. [11] who found GPF most frequently located opposite M3 (74.7\%), both in Europe and worldwide. On the other hand, Wang et al. [12] who conducted their study on Chinese recorded that the most frequent location of GPF was between M2 and M3, while Klosek and Rungruang [13], in Thais, considered the most frequent

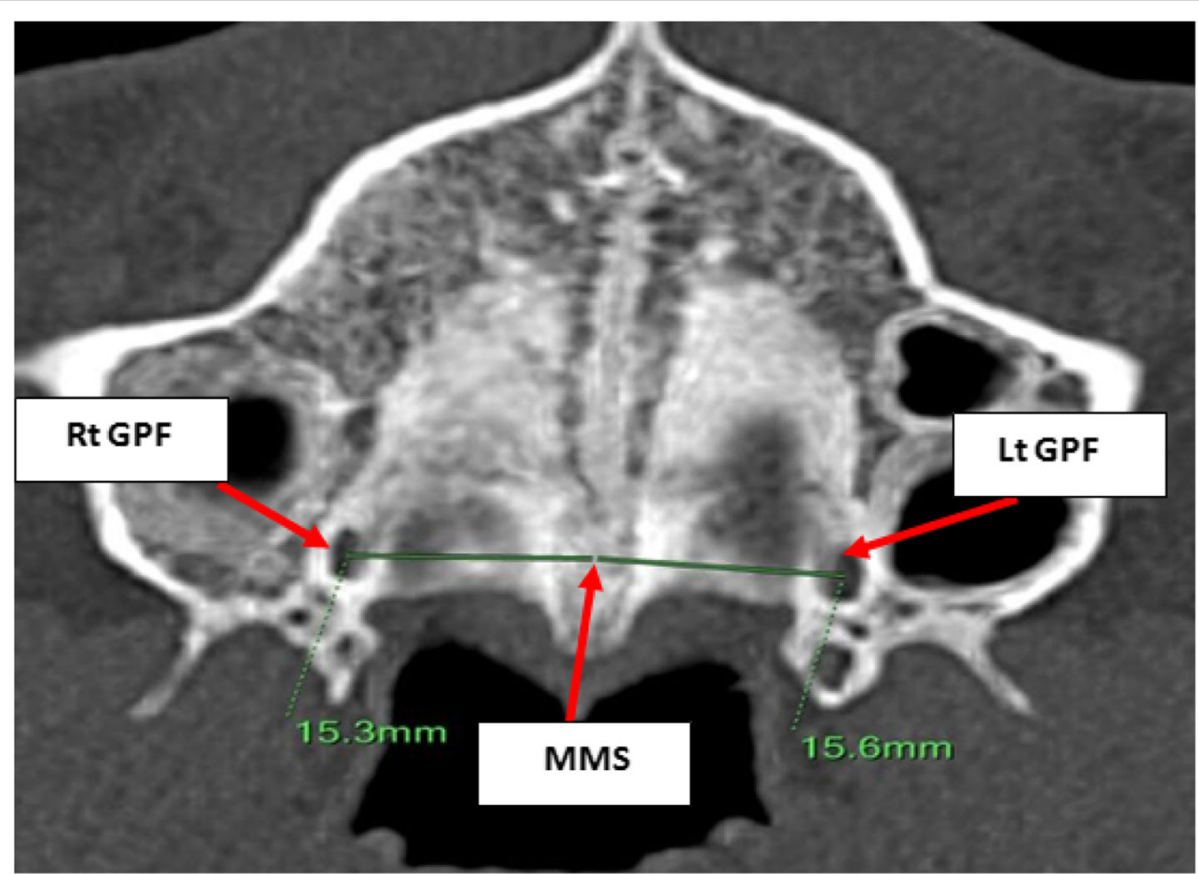

Fig. $10 \mathrm{~A}$ CT scan at the region of hard palate illustrating the shortest perpendicular distance from the center of greater palatine foramen (GPF) to midline maxillary suture (MMS) 


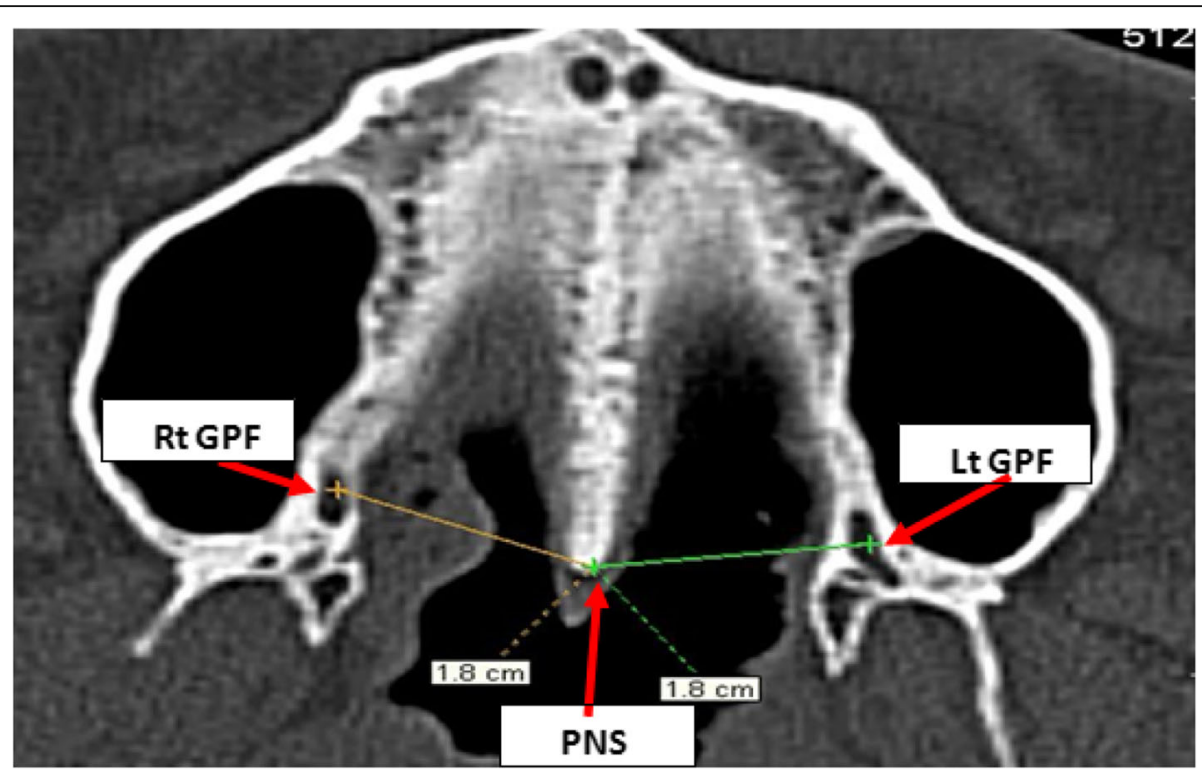

Fig. 11 A CT scan at the region of hard palate illustrating the distance from the center of greater palatine foramen (GPF) to posterior nasal spine (PNS)

location to be opposite M2. Despite numerous studies, there is still no agreement to whether the position of GPF is prone to ethnic variability. The cause of GPF position diversity may be due to the difference in the quality of procedures performed, as well as the way the GPF was related to maxillary molars $[10,11]$.

Despite differences in the methods of assessment of GPF, the dimensions did not significantly differ among studies. In our study, the mean AP diameter of GPF was
$3.94 \pm 1.13 \mathrm{~mm}$ on the right side and $4.22 \pm 1.21 \mathrm{~mm}$ on the left, while the mean LM diameter was $2.17 \pm 0.59$ $\mathrm{mm}$ on the right side and $2.28 \pm 0.74 \mathrm{~mm}$ on the left. The GPF was described as AP elongated in $90.5 \%$ and circular in $9.5 \%$. These results are almost close to most prior studies $[4,11]$. In the study of Beetge et al. [10], the mean GPF dimensions were an A-P of $5.22 \mathrm{~mm}$ and an L-M of $2.81 \mathrm{~mm}$. Shalaby et al. [9] measured the mean $\mathrm{AP}$ as $4.86 \pm 0.9 \mathrm{~mm}$ on the right side and $4.78 \pm$



Fig. 12 A CT scan at the region of hard palate illustrating the distance from the center of greater palatine foramen (GPF) to incisive fossa (IF) 
Table 9 Measurements taken from the GPF based on side

\begin{tabular}{lllll}
\hline Measurement & Side & $N$ & Distance $(\mathrm{mm})$ & $p$ value \\
\hline GPF-PBHP (mm) & Right & 200 & $3.90 \pm 1.21$ & 0.80 (NS) \\
& Left & 200 & $3.93 \pm 1.13$ & \\
GPF-MMS (mm) & Right & 200 & $14.95 \pm 1.30$ & 0.75 (NS) \\
& Left & 200 & $14.99 \pm 1.24$ & \\
GPF-PNS (mm) & Right & 200 & $16.55 \pm 1.61$ & 0.66 (NS) \\
& Left & 200 & $16.48 \pm 1.60$ & \\
GPF-IF (mm) & Right Left & 200 & $38.06 \pm 3.10$ & 0.74 (NS) \\
& & 200 & $37.96 \pm 3.17$ & \\
\hline
\end{tabular}

$1.01 \mathrm{~mm}$ on the left. The mean LM diameter was $3.02 \pm$ $0.7 \mathrm{~mm}$ on the right side and $3.01 \pm 0.9 \mathrm{~mm}$ on the left side. This minimal discrepancy could be attributed to the fact that measurements in the present study were obtained radiologically unlike Shalaby et al. [9] who performed it manually on dry skulls.

The present study is similar to the majority of studies $[11,13,14]$ in which the GPF was mostly described as anteroposteriorly elongated rather than oval in shape.

In this work, it was attempted to locate the GPF in relation to specific surrounding anatomical landmark such as posterior border of hard palate (PBHP), midline maxillary suture (MMS), posterior nasal spine (PNS), and incisive fossa (IF).
The distance between GPF-PBHP holds its importance in successful localization of GPF and prevention of accidental injury to nearby lesser palatine nerves and soft palate. Moreover, this dimension helps in localization of GPF in these cases where the third maxillary molar failed to erupt or is damaged due to any reason [15].

In the present study, the GPF-PBHP distance was 3.9 $\pm 1.21 \mathrm{~mm}$ on the right side and $3.93 \pm 1.13 \mathrm{~mm}$ on the left. This is consistent with [16] where GPF-PBHP distance was recorded as $3.63 \pm 1.91 \mathrm{~mm}$ on the right side and $3.94 \pm 1.97 \mathrm{~mm}$ on the left. Shalaby et al. [9] in their Egyptian study on dry skulls measured the GPFPBHP distance as $4.39 \pm 1.73 \mathrm{~mm}$ on the right side and $4.53 \pm 1.23 \mathrm{~mm}$ on the left. However, Shalaby et al. [9] took their measurement from the posterior edge of GPF to the point of maximum concavity on PBHP, while in the present study it was taken from the center of GPF to the shortest distance on the posterior border of hard palate.

Linear measurements in the present study showed the mean distance from the center of GPF to MMS as $14.95 \pm 1.3 \mathrm{~mm}$ on the right side and $14.99 \pm 1.24$ on the left. These values were close to radiological results of [8] in which the GPF-MMS distance was estimated as $\pm 1.45 \mathrm{~mm}$.

In the present study, the mean distance from the center of GPF to PNS was $16.55 \pm 1.61 \mathrm{~mm}$ on the right

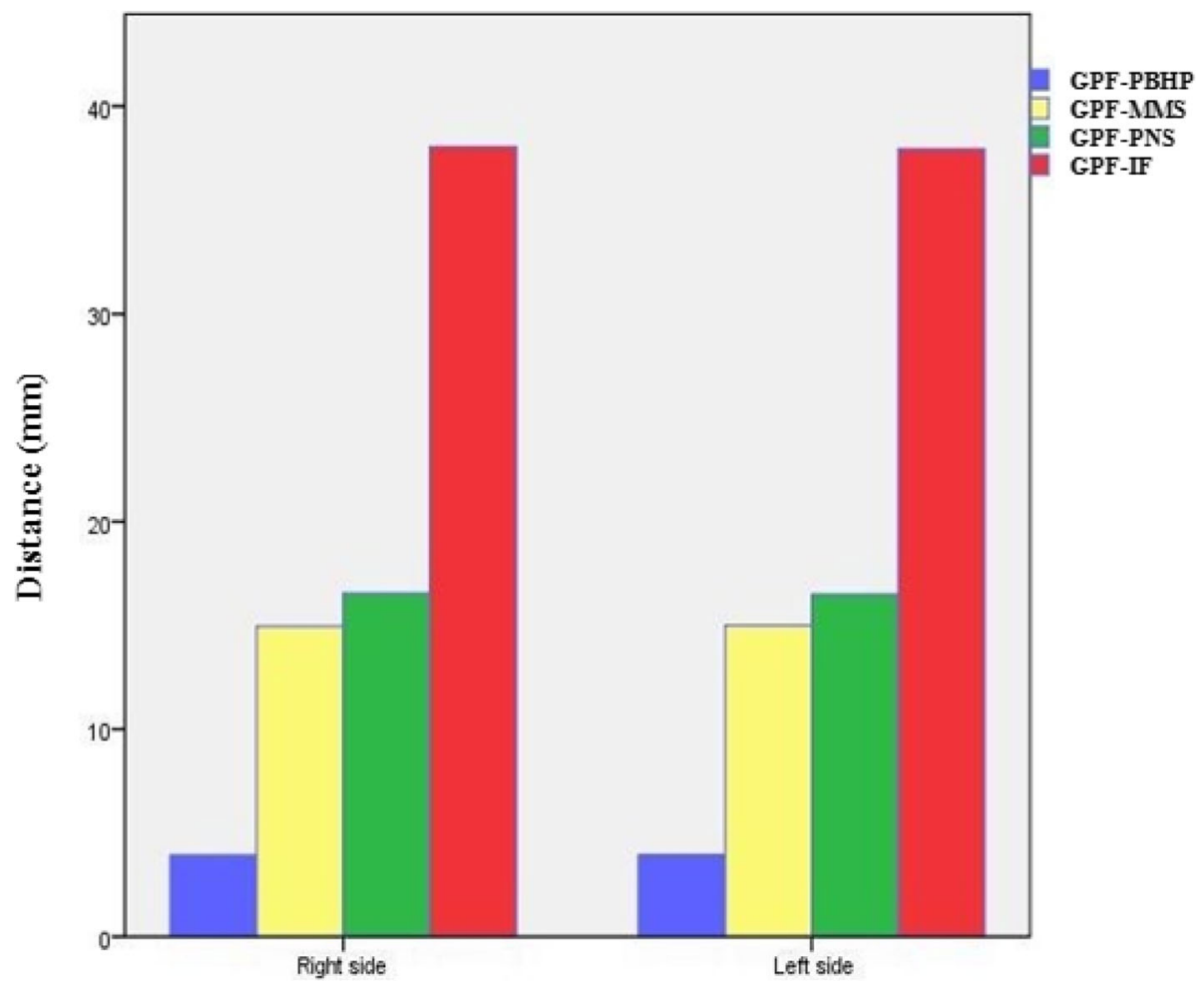

Fig. 13 Bar chart of the distances taken from the center of GPF to surrounding anatomical landmarks based on side 


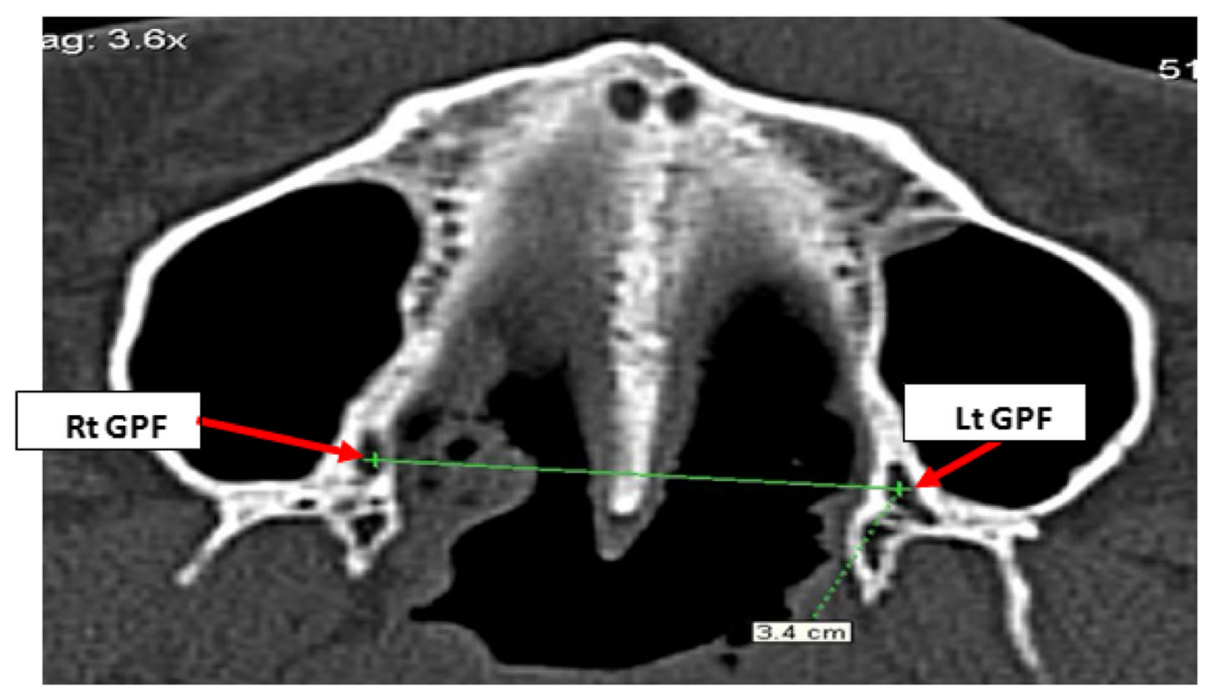

Fig. 14 A CT scan at the region of hard palate illustrating the distance from the center of greater palatine foramen to the center of opposite greater palatine foramen

side and $16.48 \pm 1.6 \mathrm{~mm}$ on the left while the distance from the center of GPF to the center of IF was $38.06 \pm$ 3.10 on the right side and $37.96 \pm 3.17$ on the left. These figures are disparate from the radiological results of Tomaszewska et al. [11], who estimated the GPF-MMS distance as $34 \pm 3 \mathrm{~mm}$ on the right side and $34.3 \pm 3.1$ on the left, though the same methodology was applied in both studies.

Surveying different studies, it could be deduced that variation exits in linear measurements in different population; even interpopulation variation could exist. These differences might be related to ethnic factor [17] or quality of procedure performed [11]. Aterkar et al. [18] pointed out that linear measurements from GPF increase in edentulism; therefore, this distance may become variable according to palate width.

In the present study, a statistically significant side difference was found in the dimensions of GPF. Previous radiological studies provided no data regarding this point $[8,11,19]$. Although Shalaby et al. [9] did not recognize a statistically significant difference between

Table 10 Measurements taken from the GPF based on gender

\begin{tabular}{lllll}
\hline Measurement & Gender & $N$ & Distance $(\mathrm{mm})$ & $p$ value \\
\hline GPF-PBHP $(\mathrm{mm})$ & Male & 100 & $4.22 \pm 1.21$ & 0.000 \\
& Female & 100 & $3.61 \pm 1.04$ & \\
GPF-MMS $(\mathrm{mm})$ & Male & 100 & $15.37 \pm 1.21$ & 0.000 \\
& Female & 100 & $14.57 \pm 1.21$ & \\
GPF-PNS (mm) & Male & 100 & $17.13 \pm 1.54$ & 0.000 \\
& Female & 100 & $15.90 \pm 1.42$ & \\
GPF-IF $(\mathrm{mm})$ & Male & 100 & $38.89 \pm 3.28$ & 0.000 \\
& Female & 100 & $37.13 \pm 2.70$ & \\
\hline
\end{tabular}

the dimensions of GPF on both sides in their study on dry skulls, radiological data should be considered more accurate in this respect.

In the present study, a statistically highly significant difference in linear measurements from the center of GPF to surrounding anatomical landmarks as well as the dimensions of GPF existed between males and females. This is similar to results of $[9,11,20]$. Male skulls are generally larger than the female ones [20].

Although Moreira et al. [21] and Nascimento et al. [22] observed a statistically significant difference between males and females regarding the distance from GPF to IF, no statistically significant difference existed regarding the distance between right and left GPF.

According to Tomaszewska et al. [11], position of GPF in relation to surrounding anatomical landmarks could be used in forensic examination to identify a person's sex. Nascimento et al. [22], though considering this method valid, simple, reproducible, and inexpensive, recommended using it only when more accurate techniques are not applicable. Although the present study adopts this point view as confirmed by the radiological results, but it would not have been accurate to rely on the general features to govern out gender of skulls without available records.

CT scans revealed one lesser palatine foramen on both sides in $75.5 \%$, two foramina in $22 \%$, three foramina in

Table 11 Mean \pm SD distance from the center of GPF to the center of opposite GPF based on gender

\begin{tabular}{lllll}
\hline Measurement & Gender & $N$ & Distance $(\mathrm{mm})$ & $p$ value \\
\hline GPF-GPF $(\mathrm{mm})$ & Male & 100 & $31.22 \pm 2.30$ & 0.000 \\
& Female & 100 & $29.54 \pm 2.12$ & \\
\hline
\end{tabular}


$2 \%$, and none in $0.5 \%$ (two skulls on the left side only). The results presented in the present study are comparable with those by Sushobhana et al. [23].

In the present study, the palatine crest was a constant finding in all CT scans. However, the percent of the presence of palatine crest was highly variable among previous studies. Jaffar and Hamadah [24] reported a $67 \%$ on both sides, Piagkou et al. [25] a $57.8 \%$ on the right side and $56.3 \%$ on the left.

The limitations of our study included the relative small number of patients, and we have not commented on the length of the canal in the present study.

\section{Conclusion}

Proper localization of GPF is important to facilitate therapeutic, local anesthetic, and surgical manipulation in the maxillofacial region. By use of multislice CT, we can assess variation in number, size, shape, and location of greater and lesser palatine foramina in relation to multiple anatomical landmarks. The GPF is most often located opposite the M3 in the majority of the cases, and the maxillary molars are the best landmarks for determination of their location.

\section{Abbreviations}

CT: Computed tomography; LPF: Lesser palatine foramina; GPF: Greater palatine foramen; M: Maxillary molar; AP: Anteroposterior; LM: Lateral-medial; PBHP: Posterior border of hard palate; MMS: Midline maxillary suture; PNS: Posterior nasal spine: IF: Center of incisive fossa

\section{Acknowledgements}

The authors would like to thank all the personnel who contributed in this study.

\section{Authors' contributions}

AS formulated the research goals, designed the study methodology, and supervised/actively participated in the research activity planning/execution. HM conducted/actively participated in the research process, performed the data collection/data analysis, and wrote the initial draft of the manuscript. HG shared in study conception and design and shared in writing and correcting the manuscript and revision. ME actively participated in research activity execution, assisted in data analysis, and largely contributed in reviewing and writing of the manuscript. TR shared in the study conception and design, acquisition of data, analysis and interpretation of data, and drafting of the manuscript. All authors read and approved the final manuscript.

\section{Funding}

This research did not receive any specific grant from funding agencies in the public, commercial, or not-for-profit sectors. There were no sources of funding for this work other than departmental resources.

\section{Availability of data and materials}

The datasets used and/or analyzed during the current study are available from the corresponding author on reasonable request.

\section{Ethics approval and consent to participate}

This study was approved by the Research Ethics Committee of the Faculty of Medicine, Cairo University on 3 May 2016. Ethics Committee reference number is not available (was not provided). Written informed consent was obtained from all the study patients before any data or scans were gathered or performed.

\section{Consent for publication}

All patients included in this research gave written informed consent to publish the data contained within this study.

\section{Competing interests}

The authors declare that they have no competing interests.

\section{Author details}

${ }^{1}$ Department of Diagnostic and Interventional Radiology, Kasr Al Ainy Faculty of Medicine, Cairo University, Cairo, Egypt. ${ }^{2}$ Department of Anatomy and Embryology, Kasr Al Ainy Faculty of Medicine, Cairo University, Cairo, Egypt. ${ }^{3}$ Department of Diagnostic and Interventional Radiology, Faculty of Medicine, National Cancer Institute, Cairo University, Cairo, Egypt.

Received: 21 April 2020 Accepted: 28 July 2020

Published online: 06 August 2020

\section{References}

1. Costa H, Zenha H, Sequeira H, Coelho G, Gomes N, Pinto C, Andresen C (2015) Microsurgical reconstruction of the maxilla: algorithm and concepts. J Plast Reconstr Aesthet Surg 68(5):e89-e104

2. Yu SK, Lee MH, Park BS, Jeon YH, Chung YY, Kim HJ (2014) Topographical relationship of the greater palatine artery and the palatal spine. Significance for periodontal surgery. J Clin Periodontol 41(9):908-913

3. Standring S, Black S, Gleeson M et al (2016) External skull. In: Gleeson M (ed) Gray's anatomy: the anatomical basis of clinical practice, vol Chapter 27 41st edn. Elsevier Health Sciences, London, pp 416-428

4. Nimigean V, Nimigean VR, Buțincu LAVINIA, Sălăvăstru DI, Podoleanu L (2013) Anatomical and clinical considerations regarding the greater palatine foramen. Romanian J Morphol Embryol 54(3 Suppl):779-783

5. Cagimni P, Govsa F, Ozer MA, Kazak Z (2017) Computerized analysis of the greater palatine foramen to gain the palatine neurovascular bundle during palatal surgery. Surg Radiol Anat 39(2):177-184

6. Varalakshmi KL, Sangeeta M (2019) Anatomical study on location of greater palatine foramen in dried adult human skull: key to successful maxillary nerve block. Int J Anat Res 7(3.1):6762-6766. https://doi.org/10.16965/ijar. 2019.219

7. Viveka S, Kumar M (2016) Radiological localization of greater palatine foramen using multiple anatomical landmarks. MOJ Anat Physiol 2(7):187189. https://doi.org/10.15406/mojap.2016.02.00073

8. Ikuta CRS, Cardoso CL, Ferreira-Júnior O, Lauris JRP, Souza PHC, RubiraBullen IRF (2013) Position of the greater palatine foramen: an anatomical study through cone beam computed tomography images. Surg Radiol Anat 35(9):837-842

9. Shalaby SA, Eid EM, Sarg NA, Sewilam AM (2015) Morphometric analysis of hard palate in Egyptian skulls. Benha Med J 32(1):59-72

10. Beetge M-M, Todorovic VS, Oettlé A, Hoffman J, van Zyl AW (2018) A microCT study of the greater palatine foramen in human skulls. J Oral Sci 60(1): 51-56. https://doi.org/10.2334/josnusd.16-0783

11. Tomaszewska IM, Kmiotek EK, Pena IZ, Średniawa M, Czyżowska K, Chrzan R, Walocha JA (2015) Computed tomography morphometric analysis of the greater palatine canal: a study of 1,500 head CT scans and a systematic review of literature. Anat Sci Int 90(4):287-297

12. Wang TM, Kuo KJ, Shih C, Ho LL, Liu JC (1988) Assessment of the relative locations of the greater palatine foramen in adult Chinese skulls. Cells Tissues Organs 132(3):182-186

13. Klosek SK, Rungruang T (2009) Anatomical study of the greater palatine artery and related structures of the palatal vault: considerations for palate as the subepithelial connective tissue graft donor site. Surg Radiol Anat 31(4): 245-250

14. Ajmani ML (1994) Anatomical variation in position of the greater palatine foramen in the adult human skull. J Anat 184(3):635-637

15. Sharma N, Varshney R, Ray S (2014) Anatomic and anaesthetic considerations of greater palatine nerve block in Indian population. Saudi J Med Med Sci 2(3):197-201

16. Rapado-González O, Suárez-Quintanilla JA, Otero-Cepeda XL, FernándezAlonso A, Suárez-Cunqueiro MM (2015) Morphometric study of the greater palatine canal: cone-beam computed tomography. Surg Radiol Anat 37(10): 1217-1224

17. Ongeti K, Hassanali J, Ogeng'o J, Saidi H (2008) Biometric features of facia foramina in adult Kenyan skulls. Eur J Anat 12(2):89-95 
18. Aterkar S, Rawal PM, Kumar P (1995) Position of greater palatine foramen in adults. J Anat Soc India 44(2):126-133

19. Asha ML, Arun Kumar G, Sattigeri Anupama V, Raja Jigna V, Diksha M (2015) Cone beam computed tomographic analysis of anatomical variations of greater palatine canal and foramen in relation to gender in South Indian population. Oral Health Dent Manag 14:384-390

20. Teixeira C, Souza V, Marques C, Silva Junior W, Pereira K (2010) Topography of the greater palatine foramen in macerated skulls. J Morphol Sci 27:88-92

21. Moreira RS, Sgrott EA, Stuker H, Alonso LG, Smith RL (2008) Palatal asymmetry during development: an anatomical study. Clin Anat 21(5):398-404

22. Nascimento L, Lima C, de Oliveira OF, Sassi C, Picapedra A, Júnior LF, Júnior ED (2012) Sex determination by linear measurements of palatal bones and skull base. J Forensic Odonto Stomatol 30(1):37-44

23. Sushobhana SRM, Singh S, Jigyasa Passey RS, Sinh A (2015) Anatomical study and clinical considerations of greater palatine foramen in adult human skulls of north Indian population. Int J Anat Radiol Surg 4(4):41-46

24. Jaffar AA, Hamadah HJ (2003) An analysis of the position of the greater palatine foramen. J Basic Med Sci 3(1):24-32

25. Piagkou M, Xanthos $T$, Anagnostopoulou S, Demesticha T, Kotsiomitis $E$, Piagkos G, Johnson EO (2012) Anatomical variation and morphology in the position of the palatine foramina in adult human skulls from Greece. J Cranio-Maxillofac Surg 40(7):e206-e210

\section{Publisher's Note}

Springer Nature remains neutral with regard to jurisdictional claims in published maps and institutional affiliations.

\section{Submit your manuscript to a SpringerOpen ${ }^{\circ}$ journal and benefit from:}

- Convenient online submission

- Rigorous peer review

- Open access: articles freely available online

High visibility within the field

- Retaining the copyright to your article

Submit your next manuscript at $\boldsymbol{\nabla}$ springeropen.com 